\title{
ROLE OF ABIOTIC FACTORS ON SEASONAL ABUNDANCE AND INFESTATION OF FRUIT FLY, BACTROCERA CUCURBITAE (COQ.) ON BITTER GOURD
}

\author{
Avadhesh Kumar Raghuvanshi, Subrata Satpathy*, Debi Shankar Mishra
}

Department of Entomology and Agricultural Zoology

Institute of Agricultural Sciences, Banaras Hindu University

Varanasi- 221005, India

Received: April 28, 2011

Accepted: February 1, 2012

\begin{abstract}
Throughout the year, there was an abundance of fruit flies in Cue-lure baited traps. Two peaks; in summer and kharif (Autumn) coincided with the $14 \mathrm{SW}$ and $43 \mathrm{SW}$ respectively. In kharif, maximum bitter gourd fruit damage (62.70\%) occurred in the 45 SW. A second peak, with $49.70 \%$ fruit damage was observed during the 15 SW period. The temperature (maximum and minimum) showed a significant positive correlation with adult abundance, fruit damage and pupal population. The temperature recorded during the preceding first, second and third weeks had a slightly greater impact than the temperature of the current week in which the fruit fly abundance had been checked. Other abiotic factors had a non-significant effect on fruit fly adult activity, fruit damage and pupal population.
\end{abstract}

Key words: Bactrocera cucurbitae, monitoring, abiotic factors, bitter gourd

\section{INTRODUCTION}

Melon fruit fly, Bactrocera cucurbitae (Coq.) (Diptera: Tephritidae) is one of the main tropical fruit flies causing considerable damage in cucurbits. B. cucurbitae has been observed to infest a wide range of crops in the Cucurbitaceae family. Yield loss varies from $30-100 \%$ (Nath and Bhusan 2006). Unlike other insects, the adult females are directly involved in initiating and causing the damage in the growing fruits. The fruit fly activity varies a lot depending mostly on the prevailing climatic conditions and the diversity of other hosts in a particular agro-ecosystem. For this reason, it is imperative to study the seasonal abundance pattern and the influence of abiotic factors on fruit fly activity for development and proper implementation of fruit fly management programmes. The present experiment was undertaken to study the para-pheromone (Cue-lure) trap mediated monitoring of adult fruit flies and the role of abiotic factors on pest activity.

\section{MATERIALS AND METHODS}

Fruit fly seasonal incidence was monitored at weekly intervals in the 2003-2004 cropping season. Cue-lure [4,(p-acetoxyphenyl)-2-butanone)] baited bottle traps were used. This experiment was conducted at the Agricultural Research Farm, Banaras Hindu University (BHU), Varanasi, India.
The traps used for monitoring fruit flies consisted of a one litre plastic mineral water bottle $(10 \mathrm{~cm}$ base diameter and $25 \mathrm{~cm}$ in height) with a screw lid. The bottles have two rectangular entry slits $(4.5 \mathrm{~cm} \times 2.5 \mathrm{~cm})$ evenly spaced on the bottom side. A wooden plywood block $(5.0 \mathrm{~cm} \times 5.0 \mathrm{~cm} \times 1.2 \mathrm{~cm}$.) was saturated with ethanol, Cue-lure, and insecticide (Malathion 50 EC) at a ratio of $6: 4: 1$. The block was soaked in the solution for one week and hung from a wire in the bottle trap near the entry slits. These para-pheromone (Cue-lure) baited traps were used for monitoring the fruit fly adult activity throughout the year (2003-2004) at the Agricultural Research Farm, BHU. Three traps, $10 \mathrm{~m}$ apart from each other, were installed in the bitter gourd field for monitoring the fruit flies.

Traps were inspected at weekly intervals in the morning hours. Recording the total adult catch was done by counting the trapped adults (live and dead) inside the bottle trap. Then, the bottle was recapped for further trapping. The Cue-lure baited wooden blocks were replaced at monthly interval. Twenty plants were randomly selected from the plot $(20 \mathrm{~m} \times 20 \mathrm{~m})$ for recording the healthy and damaged fruits, at weekly intervals as soon as the infestation started.

Observation of pupal density was done by examining the soil from the same field through a quadrate soil sampler $(50 \mathrm{~cm} \times 50 \mathrm{~cm})$ which was able to go $10 \mathrm{~cm}$ deep. Each time, 4 samples were collected from the same field. Pupal populations were counted in the laboratory after sieving 
the collected soil. The meteorological parameters from what had been the current week of observation, collecting and examining as well as the preceding first, second, and third weeks were also considered for this study. Simple correlation ( $r$ ) between the meteorological parameters (minimum and maximum temperature, relative humidity and rainfall) and adult fruit fly catch were calculated.

\section{RESULTS AND DISCUSSION}

\section{Adult abundance}

Throughout the observation periods, the adult flies remained abundant in the para-pheromone traps. In 2003-2004, the peak activity of the melon fruit fly during the summer coincided with 14 Standard Week (SW) which was 127.30 flies/trap/week (Table 1). Then, there was slight reduction in fruit fly activity. Another peak was observed during $43 \mathrm{SW}$ when the mean fly catch was 115 per trap. The fruit fly activity was drastically low during the mild temperature period particularly in the month of December to January (52 SW to $5 \mathrm{SW}$ ) when the weekly catch ranged from 0.70 to 5.00 adults/trap. The adult response to para-pheromone clearly indicates the existence of the prolonged activity periods coinciding with kharif and summer cucurbits. Moderate to high activity was noticed from $33 \mathrm{SW}$ to $47 \mathrm{SW}$ during which the weekly adult catch was above 90.00 flies/ trap/week.

In the summer, the amount of fruit flies was high, from $12 \mathrm{SW}$ to $18 \mathrm{SW}$ when the weekly adult catch was more than 85 per trap.

The adult abundance was monitored using parapheromone (Cue lure) [4 (P-acetoxyphenyl-2-butanone)] baited bottle traps. Male B. cucurbitae were prevalent throughout the monitoring period except for a few weeks in January (52 and 05 SW) when the activity was too low. Moderate to high adult fly activity was noticed twice a year; once during kharif (33 SW to $47 \mathrm{SW}$ ) and once during the summer (12 SW to $18 \mathrm{SW}$ ) season. The Cue-lure traps have been reported to attract B. cucurbitae males from mid-July to mid-November (Fang and Chang 1984; Ramsamy et al. 1987; Liu and Lin 1993; Zaman 1995). The peak activity of adult Dacus cucurbitae males in the traps baited with Cue-lure in Taiwan, were observed from October to November (Su 1984). In China, two distinct population peaks were observed during August to October and May to June (Wen 1985). The active period of B.cucurbitae in India on different cucurbitaceous hosts, has been reported to be from February to November. There were distinct population peaks in August and September with maximum damage level in Momordica charantia. The adult activity on the traps was very low from December to midFebruary, which was due to the cessation of breeding activity by adults (Lall and Singh 1969; Gupta and Verma 1992). These findings provide evidence for the distinct peaks and mild activity as observed in the present study. Furthermore, many other workers also reported peak activity of $B$. cucurbitae during different months of the year when the prevalent climatic condition was favourable. These peaks were from April to July (Kawashita et al. 2004) and mid-June to mid-November (Ramsamy et al. 1987; Liu and Lin 1993; Zaman 1995). The fruit fly population peaks as observed in the para - pheromone traps in our study also coincides with these periods. Khattak $e t$ al. (1990) and Lee et al. (1992) also observed the inactive period of B. cucurbitae to be from January to March.

Table.1. Seasonal abundance of fruit fly (B. cucurbitae Coq.) in bitter gourd crop, and meteorological parameters during 2003-2004

\begin{tabular}{|c|c|c|c|c|c|c|c|}
\hline \multirow[b]{2}{*}{ SW } & \multicolumn{3}{|c|}{ Fruit fly abundance } & \multirow[b]{2}{*}{ SW } & \multicolumn{3}{|c|}{ Fruit fly abundance } \\
\hline & fly/trap/week & $\begin{array}{c}\text { fruit damage } \\
{[\%]}\end{array}$ & $\begin{array}{c}\text { pupa/quadrate/ } \\
\text { week }\end{array}$ & & fly/trap/week & $\begin{array}{c}\text { fruit damage } \\
{[\%]}\end{array}$ & $\begin{array}{c}\text { pupa/quadrate/ } \\
\text { week }\end{array}$ \\
\hline 22 & 46.30 & 28.30 & 23.30 & 48 & 75.00 & 52.90 & 35.30 \\
\hline 23 & 41.30 & 24.90 & 29.30 & 49 & 56.30 & 38.20 & 6.00 \\
\hline 24 & 44.70 & 21.70 & 28.00 & 50 & 36.30 & 30.00 & 3.00 \\
\hline 25 & 38.30 & 20.90 & 33.70 & 51 & 11.00 & 18.50 & 2.30 \\
\hline 26 & 42.30 & 25.00 & 38.30 & 52 & 1.00 & 0.70 & 1.70 \\
\hline 27 & 43.30 & 27.70 & 39.00 & 1 & 1.70 & 0.00 & 1.30 \\
\hline 28 & 43.70 & 25.80 & 37.70 & 2 & 1.00 & 0.00 & 1.00 \\
\hline 29 & 50.00 & 30.50 & 40.00 & 3 & 0.70 & 0.00 & 0.00 \\
\hline 30 & 64.70 & 31.40 & 43.00 & 4 & 2.00 & 0.00 & 0.30 \\
\hline 31 & 74.30 & 32.50 & 42.00 & 5 & 5.00 & 0.00 & 0.00 \\
\hline 32 & 86.00 & 34.20 & 43.30 & 6 & 17.70 & 0.00 & 0.00 \\
\hline 33 & 91.30 & 39.30 & 42.70 & 7 & 40.00 & 0.00 & 0.70 \\
\hline 34 & 91.30 & 39.30 & 42.30 & 8 & 54.40 & 10.50 & 1.00 \\
\hline 35 & 94.00 & 40.00 & 39.30 & 9 & 77.70 & 15.00 & 1.30 \\
\hline 36 & 96.70 & 44.30 & 37.00 & 10 & 86.70 & 20.00 & 12.70 \\
\hline 37 & 94.30 & 43.80 & 35.30 & 11 & 82.00 & 28.00 & 18.30 \\
\hline 38 & 99.70 & 47.80 & 36.30 & 12 & 104.70 & 30.00 & 24.30 \\
\hline 39 & 105.30 & 43.90 & 36.30 & 13 & 116.70 & 40.00 & 21.30 \\
\hline 40 & 104.30 & 44.60 & 38.30 & 14 & 127.30 & 42.00 & 48.30 \\
\hline 41 & 100.70 & 48.10 & 42.70 & 15 & 97.30 & 49.70 & 41.30 \\
\hline 42 & 97.70 & 58.30 & 52.30 & 16 & 106.70 & 45.90 & 32.00 \\
\hline 43 & 115.00 & 58.00 & 51.30 & 17 & 87.30 & 46.00 & 37.7 \\
\hline 44 & 99.00 & 58.20 & 63.00 & 18 & 91.00 & 36.00 & 40.0 \\
\hline 45 & 105.00 & 62.70 & 62.30 & 19 & 80.00 & 35.30 & 41.3 \\
\hline 46 & 114.00 & 57.90 & 44.300 & 20 & 99.30 & 33.40 & 39.7 \\
\hline 47 & 96.30 & 50.00 & 41.00 & 21 & 80.00 & 34.90 & 43.3 \\
\hline
\end{tabular}

SW - Standard Week 


\section{Fruit damage [\%]}

Fruit damage (Table 1) was noticed throughout the observational period except for the winter months. During 2003-2004, the peak damage occurred in the kharif crop. More than $40 \%$ mean fruit damage was recorded from $35 \mathrm{SW}$ to $48 \mathrm{SW}$ with the maximum damage (62.7\%) in the $45 \mathrm{SW}$. No infestation was observed during the winter months i.e. January - February. The second peak of damage was noticed in summer from $13 \mathrm{SW}$ to $19 \mathrm{WS}$, with $35.3 \%$ to $40.0 \%$ fruit damage.

Borah (1996) reported $39.10 \%$ infestation in the kharif cucumber crop, while $27.60 \%$ in the summer crop. Similar findings were noted by Gupta and Verma (1992), who reported more than $50 \%$ bitter gourd fruit damage in the rainy season.

In the present study, low melon fly infestation during May-June (summer season) was observed. Similar findings have also been reported by Su (1986), Lee et al. (1992), and Dhillon et al. (2005)

Abundance of the pupal population followed a similar pattern as that of bitter gourd fruit damage (Table 1). Two peaks in the pupal population of the fruit fly were noticed. One peak was in kharif and another in summer with the maximum population of 63.0 (44 SW) and 48.3 (14 SW) per quadrate/week, respectively during 2003-2004. Pupal abundance was least during the winter months.

The pupal population was similar to the trend of the adult population catch per trap. The pupal population during January-February declined to virtually zero. The peak activity occurred from the second fortnight of April to November. In a field study in Pakistan, similar results were obtained by Khan et al. (1993).

\section{Effect of abiotic factors on fruit fly adult abundance}

The prevalence of abiotic factors in what was the current week in which fly abundance was checked, during 2003-2004, indicated that the fly catch in the para-pheromone trap had a positive correlation with maximum temperature $(r=0.58)$ (Table 2$)$. The significant effect of minimum temperature was also observed on the fly catch in the trap $(r=0.48)$. The role of other abiotic factors on the abundance of the fruit fly was non-significant.

The value of the coefficient of correlation between the fruit fly population and the weather parameters of the first preceding week, indicated a significant positive association with maximum temperature $(r=0.54)$ and minimum temperature. Maximum and minimum relative humidity reflected a non-significant negative correlation with the population of the fruit fly.

Table 2. Coefficient of correlation ( $\mathrm{r}$ ) between trap catches of the melon fruit fly (B. cucurbitae Coq.) in the bitter gourd crop, and meteorological parameters (2003-2004)

\begin{tabular}{|c|c|c|c|c|}
\hline \multirow{2}{*}{$\begin{array}{l}\text { Meteorological parameters } \\
\text { (Independent variables) }\end{array}$} & \multirow{2}{*}{ Weeks } & \multicolumn{3}{|c|}{$\begin{array}{l}\text { Fruit fly abundance } \\
\text { (dependent variables) }\end{array}$} \\
\hline & & fly/trap/week & fruit damage [\%] & upa/quadrate \\
\hline \multirow{4}{*}{ Maximum temperature $\left[{ }^{\circ} \mathrm{C}\right]$} & $\mathrm{W}_{0}$ & $0.582^{* *}$ & 0.61 & 0.51 \\
\hline & $\mathrm{W}_{1}$ & $0.545^{* *}$ & 0.66 & 0.55 \\
\hline & $\mathrm{W}_{2}$ & $0.471^{* *}$ & 0.68 & 0.55 \\
\hline & $\mathrm{W}_{3}$ & $0.386^{* *}$ & 0.69 & 0.53 \\
\hline \multirow{4}{*}{ Minimum temperature $\left[{ }^{\circ} \mathrm{C}\right]$} & $\mathrm{W}_{0}$ & $0.480^{* *}$ & 0.71 & 0.47 \\
\hline & $\mathrm{W}_{1}$ & $0.492^{* *}$ & 0.78 & 0.54 \\
\hline & $\mathrm{W}_{2}$ & $0.485^{* *}$ & 0.80 & 0.58 \\
\hline & $\mathrm{W}_{3}$ & $0.479^{* *}$ & 0.82 & 0.61 \\
\hline \multirow{4}{*}{ Maximum relative humidity [\%] } & $\mathrm{W}_{0}$ & -0.218 & -0.05 & -0.11 \\
\hline & $\mathrm{W}_{1}$ & -0.172 & -0.17 & -0.08 \\
\hline & $\mathrm{W}_{2}$ & -0.086 & -0.22 & -0.07 \\
\hline & $\mathrm{W}_{3}$ & -0.005 & -0.21 & -0.04 \\
\hline \multirow{4}{*}{ Minimum relative humidity [\%] } & $\mathrm{W}_{0}$ & -0.150 & 0.14 & -0.04 \\
\hline & $\mathrm{W}_{1}$ & -0.086 & 0.10 & 0.01 \\
\hline & $\mathrm{W}_{2}$ & 0.030 & 0.04 & 0.05 \\
\hline & $\mathrm{W}_{3}$ & 0.146 & 0.05 & 0.11 \\
\hline \multirow{4}{*}{ Total rainfall [mm] } & $\mathrm{W}_{0}$ & 0.035 & 0.25 & 0.08 \\
\hline & $\mathrm{W}_{1}$ & 0.094 & 0.25 & 0.12 \\
\hline & $\mathrm{W}_{2}$ & 0.170 & 0.26 & 0.16 \\
\hline & $\mathrm{W}_{3}$ & 0.255 & 0.28 & 0.22 \\
\hline
\end{tabular}

$\mathrm{W}_{0}$ - weather parameters pertaining to the current week

$\mathrm{W}_{1}$ - weather parameters during the 1st preceding week

$\mathrm{W}_{2}$ - weather parameters during the 2 nd preceding week

$\mathrm{W}_{3}$ - weather parameters during the 3rd preceding week

*significant at 5\% level

**significant at $1 \%$ level 
The correlation between abiotic factors with fruit damage and pupal population was the same as observed in the case of adult abundance. Maximum temperature in the what had been the current week in which fly abundance had been checked, had significant positive correlation with fruit damage $(r=0.61)$. However, the temperature which occurred during the first, secnd and third week had more influence on fruit damage with ' $r$ ' values of $0.66,0.68$ and 0.69 , respectively. The influence of minimum temperature, recorded higher correlation values $(0.71,0.78,0.80$ and 0.82$)$ for fruit damage. Maximum and minimum relative humidity and rainfall showed a nonsignificant impact on fruit damage. The temperature played a specific role in regulating the behavior of the fruit fly adults which indicates the positive correlation of prevailing temperature with the number of ovipositing females. On the other hand, the influence of relative humidity and rainfall had a negative impact on female abundance (Raghu et al. 2004). Thus, the positive influence of temperature on the abundance of ovipositing females, later increases the level of fruit damage. The effect of abiotic factors on pupal abundance also showed a similar pattern. The correlation pattern of maximum temperature recorded at the current week of checking, and at the first, second and third preceding weeks was almost similar. The $r$ value ranged from 0.51 to 0.55 . Minimum temperature also had significant positive impact on pupal abundance. However, temperature recorded in earlier weeks showed a greater impact. Other abiotic factors did not have a significant correlation on pupal abundance.

\section{REFERENCES}

Borah S.R., Dutta S.K. 1996. Comparative biology of Dacus tau (Walker) on cucurbitaceous vegetables. J. Agri. Sci. Soc. North East India 9: 159-165.

Chang L.Y., Yen C.C. 1995. Selection of food attractants to the melon fly, Dacus cucurbitae Coq. and supplementary effect of yellow insect adhesive paper. Chinese J. Entomol. 15: 35-37.

Dhillon M.K., Singh R., Naresh J.S., Sharma N.K. 2005. Influence of physico-chemical trait of bitter gourd, Momordica charantia L. on larval density and resistance to melon fruit fly, Bactrocera cucurbitae (Coq.). J. Entomol. News 129: 393-399.

Fang M.N., Chang C.P. 1984. The injury and seasonal occurrence of melon fly, Dacus cuciurbitae Coq. (Diptera : Trypetidae) in Central Taiwan. Plant Prot. Bull. Taiwan 26: 241-248.
Gupta D., Verma A.K. 1992. Population fluctuation of maggots of fruit flies, Bactrocera cucurbitae Coq. and B. tau (Walker) infesting cucurbitaceous crops. Adv. Plant Sci. 5: 518-523.

Kawashita T., Rajapakse G.B.J.P., Tsuruta K. 2004. Population survey of Bactrocera fruit flies by lure trap in Sri Lanka. Res. Bull. Plant Prot. Services, Japan 40: 297-299.

Nath P., Bhusan S. 2006. Evaluation of poison bait traps for trapping adult fruit fly. Ann. Plant Prot. Sci. 14: 297-299.

Lee L.W.Y., Hwang Y.B., Cheng C.C., Chang J.C. 1992. Population fluctuation of the melon fly, Dacus cucurbitae in NorthEastern Taiwan. Chinese J. Entomol. 12: 285-292.

Khan L., Manzoor-ul-Haq, Mohsin A.U., Inayatullah C. 1993. Biology and behaviour of melon fruit fly, Dacus cucurbitae Coq. (Diptera, Trypetidae). Pakistan J. Zool. 25: 203-208.

Khattak S.U., Afsar K., Hussain N., Khalil S.K., Alamzeb 1990. Annual population incidence of Oriental fruit fly (Dacus dorsalis Hendel) in a fruit orchard at Peshwar, Pakistan. Bangladesh J. Zool. 18: 131-138.

Lall B.S., Singh B.N. 1969. Studies on the biology and control of melon fruit fly, Dacus cucurbitae Coq. (Diptera: Trypetidae). Lab. J. Sci. Tech. 7: 14-15.

Liu Y.C., Lin J.S. 1993. The response of melon fly, Dacus cucurbitae Coq. to the attraction of 10\% MC. Plant Prot. Bul. 35: 79-88.

Inayatullah C., Khan L., Manzoor-ul-Haq, Mohsin A.U. 1991. Weather based models to predict the population densities of melon fruit fly, Dacus cucurbitae Coq. Trop. Pest Mgnt. 3: 211-215.

Raghu S., Drew R.A.I., Clarke A.R. 2004. Influence of host plant structure and micro-climate on the abundance and behavior of tephritid fruit fly. J. Insect Behav. 17: 179-190.

Ramsamy M.P., Rawanansham T., Joomaye 1987. Studies on the control of Dacus cucurbitae Coq. and Dacus demmerezi Bezze (Diptera: Tephritidae) by male annihilation. Reve Agricole et the Mauriee. 66: 1-3.

Su C.Y. 1984 . The study on the relationship between seasonal succession of male adults of melon fly, Dacus cucurbitae and the meteorological factors. J. Agril. Forestry 33: 105-109.

Su C.Y. 1986. Seasonal population fluctuations of Dacus cucurbitae in Southern Taiwan. Plant Prot. Bull. Taiwan 28: 171-178.

Wen H.C. 1985. Field studies on melon fly (Dacus cucurbitae) and attractant experiment in Southern Taiwan. J. Agril. Res. China 32: 228-235.

Zaman M. 1995. Assessment of the male population of fruit flies through kairomone baited traps and the association of the abundance level with the environmental factors. Sahad J. Agril. 11: 657-670. 